\title{
Article \\ The Relationship between HRM Strategies and Sustainable Competitive Advantage: Testing the Mediating Role of Strategic Agility
}

\author{
Mohamed Battour 1,*(D), Maged Barahma ${ }^{2}(\mathbb{D})$ and Mohammed Al-Awlaqi ${ }^{3}$ (D) \\ 1 College of Business Administration, University of Sharjah, Sharjah 27272, United Arab Emirates \\ 2 Faculty of Oil and Minerals, Aden University, Aden A 234436, Yemen; magedbarahma@gmail.com \\ 3 School of Business, Lebanese International University, Sana'a S 434360, Yemen; alzooka@gmail.com \\ * Correspondence: mbattour@sharjah.ac.ae
}

check for

updates

Citation: Battour, M.; Barahma, M.;

Al-Awlaqi, M. The Relationship

between HRM Strategies and

Sustainable Competitive Advantage: Testing the Mediating Role of

Strategic Agility. Sustainability 2021,

13,5315. https://doi.org/10.3390/

su13095315

Academic Editor: Lucian-Ionel Cioca

Received: 17 April 2021

Accepted: 3 May 2021

Published: 10 May 2021

Publisher's Note: MDPI stays neutral with regard to jurisdictional claims in published maps and institutional affiliations.

Copyright: (c) 2021 by the authors. Licensee MDPI, Basel, Switzerland. This article is an open access article distributed under the terms and conditions of the Creative Commons Attribution (CC BY) license (https:// creativecommons.org/licenses/by/ $4.0 /)$

\begin{abstract}
This study aims to investigate the impact of strategic agility on the relationship between Human Resources Management (HRM) strategies and Sustainable Competitive Advantage (SCA). A total of 227 large and medium-sized manufacturing companies were surveyed and studied. Using Structural Equation Modelling (SEM), this study found a positive and direct impact of HRM strategies on SCA. The study revealed a mediating effect of strategic agility on the relationship between HRM strategies and SCA. This study provides practical guidance for Yemeni large and medium-sized manufacturing companies to maintain SCA by focusing more on strategic agility in a turbulent business environment.
\end{abstract}

Keywords: human resources management strategies; strategic agility; sustainable competitive advantage; Yemen

\section{Introduction}

In the recent decades, companies faced the new trend of globalization that exposed them to a rapid wave of competition and a pace of profound changes. The highly competitive environment challenges most of large- and medium-sized manufacturing companies [1]. Yemen is not an exception, as globalization enforced Yemeni manufacturing companies to face severe competition from foreign companies [2]. Foreign companies dominate the local market due to their prolonged experience and their advanced production capacity. The problem does not stop here, for the position of Yemeni manufacturing companies is even worse when they try penetrating the neighbourhood regional or global markets [3]. The problem has been shown clearly when Yemen was ranked as the 139th out of 140 countries, and therefore, it is considered one of the lowest economies according to the global competitiveness report [4]. The severe competition reduced the contribution of manufacturing industry to Yemeni Gross Domestic Product from 24\% in 2010 to only $6.4 \%$ in 2015. In addition to the competition, manufacturing industry contribution was deteriorated due to their insufficient experience, inappropriate business environment, poor incentives, poor infrastructure, lack of employee training, and, as a result, lack of skilled human capital [5]. The new competition trend has created a lot of problems for the manufacturing industry in many developing countries such as Yemen [6]. These problems or challenges' roots should be discovered and solved.

Previous literature tried to prioritize the main strategies to deal with market competition. One of the main factors is the creation of SCA. The literature discussed many factors that could create SCA, such as social and technological change [7], entrepreneurial orientation and market orientation [8], investing in intangible resources and firm capabilities [9], knowledge management practices [10], marketing innovation [11], competitive intelligence [12], and total quality management $[13,14]$. Although there were many factors that could affect the creation of SCA, HRM was presented as the most prominent 
factor [15-20]. Efficient human capital can recognize the threats, exploit opportunities, and formulate proactive strategies to cope with the challenges. Controlling such threats is essential towards achieving SCA [21].

Although the relationship between HRM and SCA is well documented in the literature, the strength and the nature of this relationship is not consistent, especially when was studied among different countries and cultures. Moreover, there is scarce research focusing on the relationship between strategic agility and SCA, particularly in Yemen. Based on the insight of Resource-Based View (RBV) theory by Barney [22] and the dynamic capabilities theory by Teece et al. [23], organizational capabilities and resources contribute to a dynamism that cannot be imitated by competitors and consequently create SCA. Hence, strategic agility is one of the most important potential factors that could moderate the relationship between HRM and SCA.

This study opens a new avenue to a more comprehensive understanding of the relationship between HRM and SCA. It is expected to increase the understanding of the interaction among HRM strategies, SCA, and strategic agility through the lens of the RBV theory and the dynamic capabilities theory. Moreover, the current study is expected to provide a practical guidance on how companies can meet the competitive challenges and how to improve their competitiveness to survive in such a resource-constrained market of least developed countries, including Yemen.

This paper is organized as follows. In the next section, we review the literature and develop the associated hypothesis. In Section 3, we describe the study's methodology. In Section 4 , we conduct data analysis. In Section 5, we provide the conclusion of this research, combined with implications and suggestions for future research.

\section{Theory Development and Hypotheses}

\subsection{Human Resources Management Strategies and Sustainable Competitive Advantage}

HRM strategies are considered as a rationalised effort applied by the organizations to manage the talent pools to achieve the organizational goals. Organizations employ such strategies to form the attitude, behaviour, culture, and perception of employees in such a way that it achieves the organizational desired outcomes [24,25]. HRM strategies are critical to business success because it shapes the relationship between organizations and employees. HRM strategies help organization survive by enhancing their ability to attract, develop, motivate, and retain employees [26,27]. HRM strategies are the techniques that companies use to keep their talented employees at the right time, which help them to maintain a high level of efficient operation, to maintain continuous organizational development, and to sustain competitive advantage [28-30]. HRM strategies are pivot endeavours in creating higher performance and competitive organizations.

In the field of strategic management, SCA has been treated as one of the most important concepts that could create values for organizations. SCA could provide a long-term benefit for organizations, e.g., a company's products cannot be replicated by other companies due to superior quality, superior skills, superior capabilities, and responding to customer needs [31].

SCA could be created and maintained in many and different ways [9,31-35]. For example, Porter [36] proposed that competitive strategies could help in creating SCA though obtaining lowest cost or cost distinction positions. Moreover, Beal [37] considered that the traditional way of achieving SCA depends on the environmental structure and overall competitive strategy. Barney [22] pointed out that an organization has an SCA when it implements a value-creating strategy simultaneously with the current and future competitors. Coyne [33] argued that SCA could be achieved by exploiting the business system, position, regulatory, and quality management gaps. It also can be achieved by organization's superior skills and resources, superior efficiency, superior quality, superior innovation, and responding to customer needs $[33,38]$. In summary, due to the complexity and the diversity of its sources, SCA requires new thinking and strategic intelligence that differs from conventional thinking. 
The contribution of HRM strategies in creating SCA was widely investigated in literature. The major trend found in literature has supported the positive impact of HRM on the creation of SCA. The conceptual model of Delery and Roumpi [39] proposed a positive relationship between HRM and SCA. In line with that, Ramadan [20] emphasized that the talent management represented by human resources, organizational resources, and financial resources positively influence SCA. Velmurugan and Akhilesh [40] also emphasised that HRM strategies impact SCA by strengthening employee skill, capability, and motivation. Moreover, this positive relationship has been studied and supported in many countries and industries such as US manufacturing and service corporations, airlines companies, and health industry [41], Greece shipping industry [42], and Korean research institutions [43].

To test the relationship between HRM strategies and SCA in context of Yemen, the following hypothesis was proposed (see Figure 1):

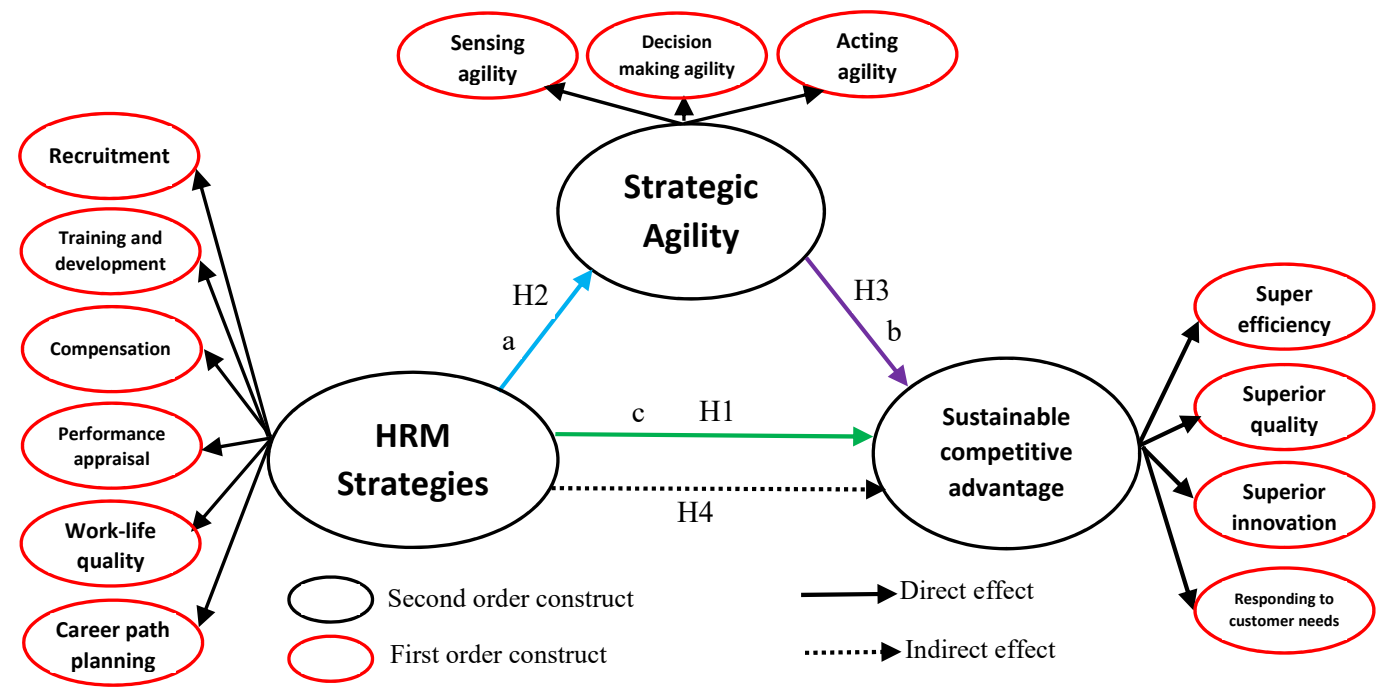

Figure 1. Theoretical framework.

Hypothesis 1 (H1). There is a direct effect of HRM strategies on SCA in Yemeni large and medium sized manufacturing companies.

\subsection{Human Resources Management Strategies and Strategic Agility}

Strategic agility is a complex construct with many aspects. Lin, Desouza, and Roy [44] defined strategic agility as the ability to continually change and adapt to business strategic directions through the development of new products and business models and creative ways of generating value. Moreover, strategic agility recognises and adapts to changes that would help the organizations to achieve greater success by exploiting potential opportunities, creating new sources of SCA, and establishing the fundamental ability for survival [45]. Organizations need to continuously anticipate, adapt, and interact with market trends and consumer needs without compromising their strategic visions [25]. Strategic agility is about the ability to change, to respond to customer's new trends, and to generate value. Thus, the interaction of staff capability, leadership, and the dynamic capabilities of strategic agility boost organization's ability to proactively adapt its reality, seize opportunities, and manage threats $[46,47]$. Strategic agility is the right approach to improve organizations' competitiveness and the ability to face future threats $[45,48,49]$.

While many studies have focused on strategic agility [14,50], very limited researches examined the relationship between HRM strategies and strategic agility [48]. For example, e Cunha et al. [51] developed six HRM domains of action that can enhance strategic agility. Crocitto and Youssef [52] emphasised the role of HRM in strategic agility through 
efficient leadership, reward system, effective training, manager strategic involvement, and strategy formulation. Similarly, Dyer and Ericksen [53] mentioned that HRM strategies contribute towards the setting of a clear organizational direction and modification of employee behaviour to continuously develop business requirements and generate innovations. Furthermore, Saha et al. [25] showed that strategic learning and HRM strategies contribute to enhancing organizational strategic agility. Bouaziz and Hachicha [16] showed that the strategy of training and development of human resources and human resources compensation strategy affect the promotion of strategic agility more than the impact of human resource evaluation strategy and recruitment strategy. There is a paucity in the research that links HRM strategies to strategic agility. Barahma et al. [15] emphasised the positive impact of HRM strategies on strategic agility and recommended further research to study the impact of these strategies in different research contexts. Moreover, Xing, Liu, Boojihawon, and Tarba [54] suggested that more research is needed to address the relationship between HRM strategies and strategic agility.

From the previous discussion, the following hypothesis was proposed (see Figure 1):

Hypothesis 2 (H2). There is a direct effect of HRM strategies on strategic agility in Yemeni large and medium sized manufacturing companies.

\subsection{Strategic Agility and Sustainable Competitive Advantage}

Strategic agility plays an important role in sustaining in the market when the organizations are competing in an unstable business environment [55]. Moreover, Teece et al. [23] stated that resources are not enough for organizations to gain superior returns in a highly competitive environment in the long term. The ability to develop new resources is the key factor for sustained competitive advantages.

The relationship between strategic agility and competitive advantage has been established in literature $[49,56]$. For example, Almahamid et al. [57] emphasised the positive role of strategic agility and knowledge exchange to achieve competitive advantage. Chen [58] tried to understand the effect of business intelligence and the flexibility of information technology infrastructure on competitive advantage via strategic agility. Furthermore, Dabiri and Gholami [56] indicated that strategic agility could affect competitive advantage through price, quality, reliability, delivery, and product innovation. Baškarada and Koronios' [47] study indicated that strategic agility has five dynamic capabilities: sensing, search, seizing, switching, and formulating. These capabilities help to play a pivot role in creating an SCA. Al-Romeedy [59] also indicated in an empirical study that strategic agility affects greatly the competitive advantage. Although a positive impact of strategic agility on SCA was traced in literature, this relationship was not established in the context of limited resources, such as the Yemeni industrial environment. To fill this gap in literature, the following hypothesis was proposed (see Figure 1):

Hypothesis 3 (H3). There is a direct effect of strategic agility on SCA in Yemeni large and medium sized manufacturing companies.

\subsection{Human Resources Management Strategies, Strategic Agility, and Sustainable Competitive Advantage}

From the previous discussion, the approval of the previous three hypotheses entails the existence of a partial mediation role of the strategic agility on the relationship between HRM strategies and SCA [60]. This complex relationship cannot be assumed unless it is supported by a strong theoretical background. The complexity of this relationship came from the fact that the impact of HRM strategies is not a simple lever that could simply create SCA [39]. Thus, we can think of many factors that could affect or alternate this relationship. One of the most important factors that could play this role is strategic agility. To create SCA, companies should respond flexibly and rapidly to their environment. Saha et al. [25] 
proposed that strategic agility plays the supporting role between HRM strategies and the SCA as a tool to achieve a rapid and flexible response to the changing environment.

In line with that, the fourth hypothesis of the current study was proposed based on the interaction between the RBV theory and the dynamic capabilities theory as recommended by Wójcik [61] and Chen [58]. The RBV theory emphasizes the importance of an organization's resources in creating a competitive advantage, yet it does not explain how to use or improve these resources. Moreover, the resource theory does not take into account the dynamic relationship between the organization's resources and the surrounding environment. The dynamic capabilities theory fills in these spaces and acts as a complementary theory to the RBV theory. The dynamic capabilities theory explains the mechanism that helps organizations develop their resources in connection with their dynamic environment [58,62]. HRM strategies are deemed as an organizational resource that returns employee behaviour in a way that enhances employee skills and ability to build a company's optimal and proactive strategies. To the best of the researchers' knowledge, there was no conceptual or empirical study that addressed the indirect relationship between HRM strategies and SCA via strategic agility as a mediating variable. To fill this gap in literature, the following hypothesis was proposed (see Figure 1):

Hypothesis 4 (H4). There is a significant mediating effect of strategic agility on the relationship between HRM strategies and SCA in Yemeni large and medium sized manufacturing companies.

\section{Methodology}

\subsection{Population and Sampling}

Studying the mediation effect of strategic agility has to be tested in a representative context that could help in generalizing the research findings. Medium and large businesses have been chosen due to their ability to alter their strategic agility as they have more resources comparing to the other types of businesses, such as small and micro-sized businesses. Moreover, conducting the research in a resource-constrained context such as Yemen could excrete clearly the impact of strategic agility due to the limited availability of other factors or options. Thus, the targeted population was chosen to be representative in a way that would help to generalized the finding of this study.

According to the official reports of the ministry of industry and trade-Yemen, there were 554 medium and large organizations in the Republic of Yemen. These organizations were classified as medium and large according to the number of years since establishment and the number of employees [63]. The 554 organizations were classified according to their industrial activities into 5 categories: food industry (345), textile industry (80), chemical industry (47), cement and tiles industry (58), and machine industry (24). A stratified random sample was selected according to these categories' proportions. A total of 227 organizations were selected, where $46 \%$ were selected from the food industry, $20 \%$ from the textile industry, $10 \%$ from the chemical industry, 15\% from the cement and tiles industry, and $9 \%$ from the machine industry. According to the power analysis, to determine the minimum satisfactory sample size of a medium effect size $\mathrm{f}^{2}=0.15$, significance/probability level $\alpha=0.05$, power level $\beta=0.08$, number of latent variables $=19$, and number of observed variables $=73$; therefore, the minimum sample size should be no less than 110 organizations (Westland, 2010). Thus, the sample size of 227 organizations of this study was considered satisfactory and representative.

\subsection{Data Collection}

The questionnaire of this study was distributed manually to the organizations. The copies of the questionnaire were collected by 5 post-graduate surveyors. The surveyors were trained on the data collection process and data collection ethics through two days course. The whole data collection process lasted for 4 months and 13 days. The data collection process for each organization lasted on average of 6 days with a maximum 
period of 14 days and a minimum period of 3 days. All organizations were followed up after 1, 3, 7, and 14 days via site visits or phone calls. The questionnaire was sent to the heads of companies and their deputies during April 2019 and August 2019. As a result, a total of 454 respondents were targeted. Only 289 questionnaires were returned, representing a response rate of $63 \%$. Due to massive missing data, a total of 18 questionnaires were discarded. Therefore, only 271 questionnaires were used, which represented a response rate of $(60 \%)$. The non-responding pattern did not show any bias problem, as it was found to be randomly distributed among the selected respondents. In summary, we can conclude that the selected sample was fairly representing the targeted population.

\subsection{Instrumentation and Variables' Measurements}

The data collection instrument is a questionnaire comprised of 3 sections. Section 1 contains 50 items measuring HRM strategies which were adapted from Laswar [64], Delery and Doty [29], Chen and Huang [65], Balkin and Gomez-Mejia [66], Jarbi [67], and Alanizi and Alfadhel [68]. HRM strategies are categorized into 6 dimensions: recruitment strategy, training and development strategy, compensation strategy, performance appraisal strategy, work-life quality strategy, and career path planning strategy [69]. Section 2 comprised of 19 items measuring strategic agility, which were adapted from the study of Alabdi [70] and Park et al. [71]. This section covered the 3 dimensions of strategic agility, namely, sensing agility, decision-making agility, and acting agility, as stated by Park et al. [71]. The third section is devoted to SCA measurement using 16 items adapted from Shabaan [72]. All of the items in the 3 sections were measured using a 5-point Likert scale that takes the values from $5=$ strongly agree to $1=$ strongly disagree. In summary, the questionnaire of this study was organized into 3 sections that measure 3 constructs: HRM strategies, strategic agility, and SCA.

\subsection{Pilot Study}

To reach its final version, the questionnaire of this study has gone through pilot testing. After the initial selection of the items for each construct, the questionnaire was tested through a panel discussion that consists of 9 experts in the fields of strategic management and HRM. Some items have been modified in compliance with their opinions and recommendations. After the panel discussion, a pilot study was conducted on the study's survey. The pilot study's data was obtained from 31 respondents who were the heads and deputies of some manufacturing companies. The data was processed further and used to test the reliability of the survey using the Cronbach's alpha test. Accordingly, 3 items were dropped from the recruitment strategy to improve the alpha value from 0.383 to 0.906 . The final alpha scores were: 0.914 for HRM strategies, 0.907 for strategic agility, and 0.861 for SCA. Therefore, the finalized measurement of the proposed model consisted of 82 items with 13 dimensions. The questionnaire was further tested for the normality problem. The skewness-value was ranged from -0.050 to +0.063 , and the kurtosis-value was ranged from -0.114 to +0.728 , suggesting that the data was normally distributed.

\subsection{Data Analysis and Hypothesis Testing Techniques}

To test the proposed model and the study's hypotheses, the covariance-based SEM (CB-SEM) technique was applied through IBM AMOS 23 and IBM SPSS software. Three statistical processing methods were used: Exploratory Factor Analysis (EFA) to make sure that the constructs in this study reached a simple structure [73], Confirmatory Factor Analysis (CFA) to ascertain the quality of the model's conformance to the indicators [73], and SEM to test the main hypotheses.

The mediation effect was tested following Baron and Kenny's [60] approach. In this approach, the hypotheses $\mathrm{H} 1, \mathrm{H} 2$, and $\mathrm{H} 3$ should be tested for any significant impact. $\mathrm{H} 1$ and $\mathrm{H} 2$ should show significant scores; otherwise, the mediation effect could not be confirmed. If $\mathrm{H} 1$ shows a significant impact, then we have a partial mediation effect; otherwise, the mediating effect would be described as perfect. According to this approach, 
the mediation magnitude could be calculated by multiplying $(\mathrm{a} \times \mathrm{b})$ in the main model (see Figure 1). This study used the Variance Accounted for (VAF) to analyse the strength of the mediator effect. According to [73], partial mediation occurs when the VAF is greater than $20 \%$ and less than $80 \%$. Convergent validity, discriminant validity, and internal consistency were tested following the procedure presented by [73].

\subsection{Control Variables}

Reviewing the literature directed the researchers' attention to a very important variable that could play the role of confounding the relationship between HRM and SCA. The product life cycle has been chosen because (1) it could have an effect on both the HRM strategies and the creation of SCA [74], (2) it is related to the other conventional control variables such as the size and sales of the organization, and (3) it is pivot variable, especially for the manufacturing sector. The product life cycle was measured using 3 levels: growing, matured, and declining depending on a 3-year sales pattern. HRM and SCA were manipulated and recalculated into new variables of 2 levels: high and low. The data on the product life cycle was available for only 108 businesses. Cochran-Mantel-Haenszel tests were used to test the partial association between HRM and SCA, given the product a life cycle. Cochran's test shows a significant association with $\chi(1)=7.331, p=0.007$. Similarly, Mantel-Haenszel shows almost the same significant score of $\chi(1)=6.141, p=0.013$. The previous discussion confirmed the association between HRM and SCA in the existence of the proposed confounding variable.

\section{Findings}

\subsection{Measurement Model Assessment}

The quality of the measurement model in terms of validity and reliability was assessed prior to testing the structural model [73]. This study conducted the EFA and then the CFA to purify the measurement. EFA was conducted with factor loadings of greater than 0.40. Moreover, all items that were saturated or loaded on more than one factor were deleted. As a result, items 9, 8, and 13 were trimmed away from the dependent variable (SCA) and items 6 and 9 from the independent variable (HRM strategies). KMO and Bartlett's test was conducted to test the sampling adequacy. KMO and Bartlett's test confirmed the suitability of conducting a factor analysis because it showed that all variables are correlated enough. The KMO and Bartlett's test showed significant values of 0.914 for HRM strategies, 0.925 for strategic agility, and 0.941 for SCA. In the second step, a CFA was conducted to test the assessment-of-fit between observed data and the theoretical model, which specifies hypothesised causal relations between latent factors and their observed indicator variables. EFA produced 13-factor solution explaining $72.654 \%$ of the variance. A first-order CFA was conducted to estimate the validity and reliability of the 13 dimensions. HRM strategies were represented in seven dimensions: recruitment strategy, training and development strategy, compensation strategy, performance appraisal strategy, worklife quality strategy, and career path planning strategy. Strategic agility was represented by three dimensions: sensing agility, decision-making agility, and acting agility. SCA was represented by four dimensions: responding to customer needs, superior efficiency, superior quality, and superior innovation. The CFA showed satisfactory results on the goodness-of-fit test. The Chi-square results are as follows: $4124.834, \mathrm{df}=2512, p=0.000$, CIMIND $=1.642, \mathrm{CFI}=0.906, \mathrm{TLI}=0.90, \mathrm{RMSEA}=0.049, \mathrm{GFI}=0.880, \mathrm{AGFI}=0.850$, $\mathrm{IFI}=0.912$, and NFI $=0.942$.

Table 1 shows that the average variance extracted is higher than 0.50 , which fulfilled the criteria of convergent validity. Moreover, the internal consistency of variables is also confirmed as the calculated values exceeded the recommended value (0.7). The correlation, which lies at the interval of (0.135-0.673), is lower than the threshold value (0.85). Thus, the external correlation among the factors is less than the inner bonding value of similar factors, which indicates that the discriminant validity is achieved for all of the study's constructs. 
Table 1. Factor Loading, Cronbach's alpha, CR, and AVE.

\begin{tabular}{|c|c|c|c|c|c|}
\hline Variables & Items & Factor Loading & $\begin{array}{c}\alpha \\
(>0.7)\end{array}$ & $\begin{array}{c}\text { CR } \\
(>0.7)\end{array}$ & $\begin{array}{c}\text { AVE } \\
(>0.5)\end{array}$ \\
\hline HRM strategies & & & 0.959 & & \\
\hline \multirow[t]{9}{*}{ Compensation strategy } & SCOMPEN9 & 0.866 & 0.954 & 0.955 & 0.701 \\
\hline & SCOMPEN8 & 0.817 & & & \\
\hline & SCOMPEN7 & 0.801 & & & \\
\hline & SCOMPEN6 & 0.888 & & & \\
\hline & SCOMPEN5 & 0.788 & & & \\
\hline & SCOMPEN4 & 0.811 & & & \\
\hline & SCOMPEN3 & 0.882 & & & \\
\hline & SCOMPEN2 & 0.855 & & & \\
\hline & SCOMPEN1 & 0.822 & & & \\
\hline \multirow[t]{9}{*}{ Training and development strategy } & & & 0.923 & 0.914 & 0.574 \\
\hline & STRAIN2 & 0.852 & & & \\
\hline & STRAIN3 & 0.897 & & & \\
\hline & STRAIN4 & 0.855 & & & \\
\hline & STRAIN5 & 0.710 & & & \\
\hline & STRAIN7 & 0.672 & & & \\
\hline & STRAIN8 & 0.683 & & & \\
\hline & STRAIN10 & 0.692 & & & \\
\hline & STRAIN11 & 0.657 & & & \\
\hline \multirow[t]{8}{*}{ recruitment strategy } & & & 0.879 & 0.880 & 0.513 \\
\hline & SEMP3 & 0.661 & & & \\
\hline & SEMP4 & 0.663 & & & \\
\hline & SEMP5 & 0.659 & & & \\
\hline & SEMP6 & 0.676 & & & \\
\hline & SEMP7 & 0.760 & & & \\
\hline & SEMP8 & 0.830 & & & \\
\hline & SEMP9 & 0.745 & & & \\
\hline \multirow[t]{5}{*}{ Performance appraisal strategy } & & & 0.909 & 0.870 & 0.628 \\
\hline & SEVALU2 & 0.809 & & & \\
\hline & SEVALU3 & 0.849 & & & \\
\hline & SEVALU4 & 0.801 & & & \\
\hline & SEVALU7 & 0.703 & & & \\
\hline Strategy of work-life quality & & & 0.863 & & \\
\hline \multirow[t]{3}{*}{ Working environment condition } & SWFQD14 & 0.781 & 0.829 & 0.828 & 0.617 \\
\hline & SWFQD13 & 0.760 & & & \\
\hline & SWFQD12 & 0.814 & & & \\
\hline \multirow[t]{4}{*}{ Work-life balance } & SWFQB5 & 0.703 & 0.840 & 0.848 & 0.586 \\
\hline & SWFQB6 & 0.875 & & & \\
\hline & SWFQB7 & 0.679 & & & \\
\hline & SWFQB8 & 0.789 & & & \\
\hline \multirow[t]{3}{*}{ initially organizational work } & SWFQC9 & 0.663 & 0.806 & 0.832 & 0.627 \\
\hline & SWFQC10 & 0.879 & & & \\
\hline & SWFQC11 & 0.817 & & & \\
\hline \multirow[t]{4}{*}{ Career path planning strategy } & SCPL1 & 0.874 & 0.893 & 0.882 & 0.653 \\
\hline & SCPL2 & 0.845 & & & \\
\hline & SCPL3 & 0.739 & & & \\
\hline & SCPL4 & 0.766 & & & \\
\hline Mediating Variable Strategic Agility & & & 0.957 & & \\
\hline \multirow[t]{4}{*}{ Sensing agility } & AGILITY1INV & 0.960 & 0.977 & 0.976 & 0.909 \\
\hline & AGILITY2INV & 0.990 & & & \\
\hline & AGILITY3INV & 0.944 & & & \\
\hline & AGILITY4INV & 0.919 & & & \\
\hline
\end{tabular}


Table 1. Cont.

\begin{tabular}{|c|c|c|c|c|c|}
\hline Variables & Items & Factor Loading & $\begin{array}{c}\alpha \\
(>0.7)\end{array}$ & $\begin{array}{c}\text { CR } \\
(>0.7)\end{array}$ & $\begin{array}{r}\text { AVE } \\
(>0.5)\end{array}$ \\
\hline \multirow[t]{7}{*}{ Decision-making agility } & & & 0.946 & 0.946 & 0.747 \\
\hline & AGILITY5 & 0.844 & & & \\
\hline & AGILITY6 & 0.885 & & & \\
\hline & AGILITY7 & 0.902 & & & \\
\hline & AGILITY8 & 0.903 & & & \\
\hline & AGILITY9 & 0.888 & & & \\
\hline & AGILITY10 & 0.756 & & & \\
\hline \multirow[t]{10}{*}{ Acting agility } & & & 0.943 & 0.938 & 0.629 \\
\hline & AGILITY11 & 0.815 & & & \\
\hline & AGILITY12 & 0.791 & & & \\
\hline & AGILITY13 & 0.827 & & & \\
\hline & AGILITY14 & 0.754 & & & \\
\hline & AGILITY15 & 0.810 & & & \\
\hline & AGILITY16 & 0.802 & & & \\
\hline & AGILITY17 & 0.776 & & & \\
\hline & AGILITY18 & 0.791 & & & \\
\hline & AGILITY19 & 0.767 & & & \\
\hline Sustainable competitive advantage & & & 0.930 & & \\
\hline \multirow[t]{3}{*}{ Responding to customer needs } & COMPETITIV14 & 0.821 & 0.903 & 0.890 & 0.729 \\
\hline & COMPETITIV15 & 0.895 & & & \\
\hline & COMPETITIV16 & 0.843 & & & \\
\hline \multirow{5}{*}{ Superior efficiency } & & & 0.854 & 0.907 & 0.710 \\
\hline & COMPETITIV1 & 0.798 & & & \\
\hline & COMPETITIV2 & 0.924 & & & \\
\hline & COMPETITIV3 & 0.881 & & & \\
\hline & COMPETITIV4 & 0.758 & & & \\
\hline \multirow[t]{4}{*}{ Superior quality } & & & 0.883 & 0.886 & 0.722 \\
\hline & COMPETITIV5 & 0.833 & & & \\
\hline & COMPETITIV6 & 0.847 & & & \\
\hline & COMPETITIV7 & 0.868 & & & \\
\hline \multirow[t]{4}{*}{ Superior innovation } & & & 0.832 & 0.885 & 0.720 \\
\hline & COMPETITIV12 & 0.769 & & & \\
\hline & COMPETITIV11 & 0.855 & & & \\
\hline & COMPETITIV10 & 0.915 & & & \\
\hline
\end{tabular}

\subsection{Structural Model Assessment}

The structural model shows the relationship between the latent variables that were hypothesized in the proposed model in Figure 1. In order to test the hypotheses of the current study, SEM is used to ascertain the model's efficiency with its conformity with the data. The obtained fit indices results were $p<0.5$. They are: Chi-square 4138.553, DF $=2522$, $p=0.000, \mathrm{CIMIND}=1.641, \mathrm{CFI}=0.901, \mathrm{TLI}=0.90, \mathrm{RMSEA}=0.049, \mathrm{GFI}=0.70, \mathrm{AGFI}=0.69$, $\mathrm{IFI}=0.901$, and NFI $=0.78$. Thus, the results of goodness-of-fit indices indicated irrefutable evidence of an adequate model fit to the data, as shown in Figure 2.

\subsection{Hypotheses Testing}

After verifying the model fit, this study examined the direct and indirect effects among the study variables. The results of the structural model are illustrated in Table 2. The results show a significant direct effect of HRM strategies on SCA $(\beta=0.33 ; p<0.05)$ in Yemeni large- and medium-sized manufacturing companies. There is also a significant direct effect of HRM strategies on strategic agility $(\beta=0.64 ; p<0.05)$. Furthermore, there is a significant direct effect of strategic agility on SCA $(\beta=0.40 ; p<0.05)$. Hence, $\mathrm{H} 1, \mathrm{H} 2$, and $\mathrm{H} 3$ were supported. Moreover, the results of squared multiple correlations confirmed that HRM strategies explained $40 \%$ of the variance of strategic agility and $44.1 \%$ of the variance of SCA. 


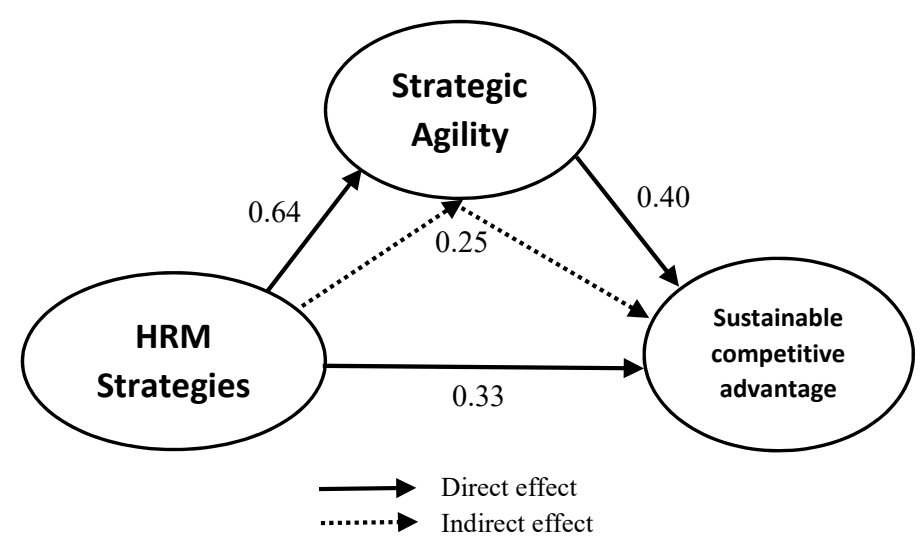

Figure 2. Structural equation modelling (SEM).

Table 2. Direct impact between the study variables.

\begin{tabular}{cccccccc}
\hline Variable & Path & Variable & Path & S.E. & C.R. & $p$ Value & Result \\
\hline SCA & $\leftarrow$ & HRM strategies & 0.330 & 0.133 & 3.650 & $* * *$ & Significant \\
\hline Strategic agility & $\leftarrow$ & HRM strategies & 0.64 & 0.112 & 6.373 & $* * *$ & Significant \\
\hline SCA & $\leftarrow$ & strategic agility & 0.40 & 0.121 & 4.324 & $* * *$ & Significant \\
\hline *** significant if less than 0.05. & & & & & &
\end{tabular}

\subsection{Mediation Effect}

As explained in Section 3, testing the mediation effect has to go through testing more than one relationship of the direct and indirect effects. Table 3 shows the results of these relationships. It starts with presenting the hypothesis to be tested. The $p$-value column shows a score of 0.000 , which indicates the rejection of the null hypothesis of having no indirect impact of HRM on the SCA. The second column shows the corresponding T-value of the previous test, which is, in this case, 3.65. The indirect column shows the score of the indirect impact of HRM on SCA. The indirect impact shows a magnitude of 0.256 . The column of the indirect effect test shows a score of 0.001 , which indicates that the indirect effect of HRM on the SCA is significant. This impact is significant, as shown in the indirect effect test results. According to these results, the total effect of HRM on SCA would be the total score of 0.586 , which results from summing up the direct effect of 0.256 and the indirect effects of 0.33 . The VAF shows a score of 0.563 , which equals the direct effect $(0.33)$ divided by the total effect. Thus, $56.3 \%$ of HRM strategies' effect on SCA is explained through the partial mediator variable (strategic agility) in Yemeni large- and mediumsized manufacturing companies. Furthermore, the validity of the indirect relationship of the fourth main hypothesis was explained through the Bias-corrected percentile method for upper and lower values, which were, respectively, 0.624 and 0.209 . Therefore, it is considered in a good range, as shown in Table 3.

As shown in Table 3, H4 is supported. Therefore, HRM strategies have an indirect effect on SCA through the strategic agility variable. In other words, HRM strategies have a causal relationship with SCA through strategic agility. The theoretical model proposed in the current study fits the data collected from the target population. In turn, the results supported that strategic agility is a mediator variable in explaining the relationship between HRM strategies and SCA. 
Table 3. Testing Significance of the Indirect Effect (Mediation).

\begin{tabular}{|c|c|c|c|c|c|c|c|c|c|}
\hline \multirow[b]{2}{*}{ Hypothesis } & \multirow[b]{2}{*}{$\begin{array}{c}p- \\
\text { Value }\end{array}$} & \multirow[b]{2}{*}{$\begin{array}{l}\text { T-Value } \\
\text { (CR) }\end{array}$} & \multicolumn{3}{|c|}{$\begin{array}{l}\text { Bias-Corrected Percentile } \\
\text { Method }\end{array}$} & \multicolumn{2}{|c|}{$\begin{array}{c}\text { Bias-Corrected } \\
\text { Percentile Method }\end{array}$} & \multirow{2}{*}{$\begin{array}{c}\begin{array}{c}\text { Indirect Effect Test } \\
\text { Results }\end{array} \\
\text { (Bootstrap Stand } \\
\text { Error) (TWO) Tailed } \\
\text { Significance (BC) }\end{array}$} & \multirow[b]{2}{*}{ Result } \\
\hline & & & Indirect & Direct & $\begin{array}{l}\text { Total } \\
\text { Effect }\end{array}$ & $\begin{array}{l}\text { Upper } \\
\text { (BC) }\end{array}$ & $\begin{array}{l}\text { Lower } \\
\text { (BC) }\end{array}$ & & \\
\hline $\begin{array}{c}\text { Indirect positive } \\
\text { relationship between HRM } \\
\text { strategies and SCA through } \\
\text { the strategic agility as a } \\
\text { mediating }\end{array}$ & 0.000 & 3.650 & 0.256 & 0.33 & 0.586 & 0.624 & 0.209 & 0.001 & $\begin{array}{l}\text { Partial } \\
\text { mediation }\end{array}$ \\
\hline
\end{tabular}

\section{Discussion}

This paper responded to an important gap found in literature, as there was no conceptual or empirical study that addressed the indirect relationship between HRM strategies and SCA via strategic agility as a mediating variable. There is a paucity in the research that links HRM strategies to strategic agility. Barahma et al. [15] recommended further research to study the impact of these strategies in different research contexts. Moreover, Xing, Liu, Boojihawon, and Tarba [54] suggested that more research is needed to address the relationship between HRM strategies and strategic agility. Thus, this study was conducted to fill in this essential gap.

Following the first objective of achieving a comprehensive understanding of the relationship between HRM and SCA and strategic agility through the lens of the RBV theory and the dynamic capabilities theory, this study examines the mediating role of strategic agility on the relationship between HRM strategies and SCA. The findings supported the mediating effect of strategic agility on the relationship between HRM strategies and SCA. These results are consistent with previous studies on SCA [20,35,75-77]. Moreover, the findings of this study supported the significant impact of HRM strategies on strategic agility. This result was expected, and it showed concurrence with previous studies $[15,16]$. Furthermore, testing the third hypothesis of this study supported a direct impact of strategic agility on SCA. This result is in line with previous studies and supports the general theme found in previous literature $[47,56,57,59,78]$.

\section{Conclusions}

\subsection{Study Theoretical and Practical Implications}

The findings of this study contribute theoretically in explaining the relationships among HRM strategies, strategic agility, and sustainable competitive advantage. This study developed the hypotheses based on the RBV theory and the dynamic capabilities theory to test the mediating role of strategic agility between HRM strategies and SCA.

Following the second objective of providing practical guidance on how companies can meet the competition challenges, it practically provides guidance for Yemeni large- and medium-sized manufacturing companies to maintain SCA by focusing more on strategic agility. Companies should also consider strategic agility as a tool to anticipate and manage changes, embrace risks to create more opportunities, and increase company readiness to face direct competition. Furthermore, the importance of HRM strategies in achieving SCA among Yemeni large- and medium-sized manufacturing companies will not be ideally realised if it is not combined with strategic agility. The Yemeni large- and medium-sized manufacturing companies can achieve SCA by attracting qualified human resources with the potential to meet the job requirements and maintaining and developing their skills and abilities. These findings highlight the critical roles of compensation strategy, performance appraisal strategy, work-life quality strategy, and career path planning strategy for maintaining SCA. This could practically be applied because HRM strategies could modify employee's behaviour to continuously develop business models in Yemeni largeand medium-sized manufacturing companies. This would align the internal processes to meet future challenges. 


\subsection{Study Limitations}

The study focused on the medium- and large-sized businesses, which are considered in fact a very proper context that could help to understand the relationships among HRM, strategic agility, and SCA, yet the study did not cover other types of industries, such as small-sized businesses. Using the cross-sectional type of data could hinder the ability to understand the dynamic relationships among the study's variables. In addition to this, strategic agility has been studied as a mediating variable, and some other variables were ignored due to the scope of this study. Future research could apply the same conceptual model in different contexts, such as small-sized companies or in some other developed countries.

\subsection{Future Research}

Future research might examine the dynamic relationship in this conceptual model using a longitudinal design. It is also recommended to use other variables rather than strategic agility as mediating variables on the relationship between HRM strategies and SCA, such as organizational effectiveness, organizational commitment, and innovation.

Author Contributions: Conceptualization, M.B. (Mohamed Battour) and M.B. (Maged Barahma); methodology M.B. (Mohamed Battour); M.B. (Maged Barahma) and M.A.-A.; software, M.B. (Maged Barahma); validation, M.B. (Mohamed Battour) and M.B. (Maged Barahma); formal analysis, M.A.-A.; investigation, M.B. (Mohamed Battour); resources, M.B. (Mohamed Battour); data curation, M.A.-A.; writing-original draft preparation M.B. (Mohamed Battour); writing-review and editing, M.B. (Mohamed Battour) and M.A.-A.; funding acquisition, M.B. (Mohamed Battour). All authors have read and agreed to the published version of the manuscript.

Funding: This research received no external funding.

Institutional Review Board Statement: Not applicable.

Informed Consent Statement: Not applicable.

Data Availability Statement: Not applicable.

Conflicts of Interest: The authors declare no conflict of interest.

\section{References}

1. Aamer, A.M.; Al-Awlaqi, M.A.; Mandahawi, N. Insights into the Reasons behind the Limited Implementation of ISO 9001 Certification: Empirical Evidence from Yemen. TQM J. 2020. [CrossRef]

2. Al-Awlaqi, M.A.; Aamer, A.M. An Integrated MUSA to Measure Health Care Service Quality from a Patient's Perspective in a Resource-Constrained Setting. Int. J. Health Plann. Manag. 2020, 35, e119-e132. [CrossRef] [PubMed]

3. Aamer, A.M. Manufacturing in Yemen: Challenges and Obstacles. J. Acad. Res. Econ. 2015, 7, 119-142.

4. Global Competitiveness Report. World Economic Forum. Available online: https://www.weforum.org/reports/the-globalcompetitveness-report (accessed on 7 December 2019).

5. AlQershi, N.; Bin Abas, Z.; Mokhtar, S.S.M. The Mediating Effect of Human Capital on the Relationship Between Strategic Innovation and the Performance of Manufacturing SMEs In Yemen. Organ. Mark. Emerg. Econ. 2019, 10, 57-77. [CrossRef]

6. Aamer, A.M. Outsourcing in Non-Developed Supplier Markets: A Lean Thinking Approach. Int. J. Prod. Res. 2018, 56, 6048-6065. [CrossRef]

7. Haseeb, M.; Hussain, H.I.; Kot, S.; Androniceanu, A.; Jermsittiparsert, K. Role of Social and Technological Challenges in Achieving a Sustainable Competitive Advantage and Sustainable Business Performance. Sustainability 2019, 11, 3811. [CrossRef]

8. Pratono, A.H.; Darmasetiawan, N.K.; Yudiarso, A.; Jeong, B.G. Achieving Sustainable Competitive Advantage through Green Entrepreneurial Orientation and Market Orientation: The Role of Inter-Organizational Learning. Bottom Line 2019, 32, 2-15. [CrossRef]

9. Khan, S.Z.; Yang, Q.; Waheed, A. Investment in Intangible Resources and Capabilities Spurs Sustainable Competitive Advantage and Firm Performance. Corp. Soc. Responsib. Environ. Manag. 2019, 26, 285-295. [CrossRef]

10. Mahdi, O.R.; Nassar, I.A.; Almsafir, M.K. Knowledge Management Processes and Sustainable Competitive Advantage: An Empirical Examination in Private Universities. J. Bus. Res. 2019, 94, 320-334. [CrossRef]

11. Quaye, D.; Mensah, I. Marketing Innovation and Sustainable Competitive Advantage of Manufacturing SMEs in Ghana. Manag. Decis. 2018, 57, 1535-1553. [CrossRef]

12. Casado Salguero, G.; Fernández Gámez, M.Á.; Aldeanueva Fernández, I.; Ruíz Palomo, D. Competitive Intelligence and Sustainable Competitive Advantage in the Hotel Industry. Sustainability 2019, 11, 1597. [CrossRef] 
13. Aamer, A.M.; Al-Awlaqi, M.A.; Alkibsi, S.M. TQM Implementation in a Least Developed Country: An Exploratory Study of Yemen. TQM J. 2017, 29, 467-487. [CrossRef]

14. Chen, R.; Lee, Y.-D.; Wang, C.-H. Total Quality Management and Sustainable Competitive Advantage: Serial Mediation of Transformational Leadership and Executive Ability. Total Qual. Manag. Bus. Excell. 2020, 31, 451-468. [CrossRef]

15. Barahma, M.M.; ALi, K.B.; Nashief, M.; Al-Awlaqi, M.A. The Impact of Human Resources Management Strategies on the Strategic Agility: A Field Study in Large and Medium Yemeni Manufacturing Sector. J. Soc. Sci. COESRJ-JSS 2019, 8, 611-629. [CrossRef]

16. Bouaziz, F.; Smaoui Hachicha, Z. Strategic Human Resource Management Practices and Organizational Resilience. J. Manag. Dev. 2018, 37, 537-551. [CrossRef]

17. Bułat, E. Human Resource Management Practices That Translate into Sustainable Competitive Advantage. Cent. Eur. Rev. Econ. Manag. 2019, 3, 115-132. [CrossRef]

18. Latukha, M.; Lisina, P.; Panibratov, Y. Developing Sustainable Competitive Advantage of a Firm through Human Resource Management Practices: A Competence-Based Approach. Glob. Bus. Econ. Rev. 2018, 21, 96-119. [CrossRef]

19. Muduli, A. Workforce Agility: Examining the Role of Organizational Practices and Psychological Empowerment. Glob. Bus. Organ. Excell. 2017, 36, 46-56. [CrossRef]

20. Ramadan, W.H. The Influence of Talent Management on Sustainable Competitive Advantage of Small and Medium Sized Establishments; E-Leader: Berlin, Germany, 2012.

21. Alwehabie, A.M. Criteria for Measuring the Efficiency and Effectiveness of Human Resources Management Strategy and Its Relation to Institutional Performance at Al Rajhi Bank at Al Qassim in Saudi Arabia from the Employees' Point of View. Int. J. Bus. Manag. 2017, 12, 111. [CrossRef]

22. Barney, J. Firm Resources and Sustained Competitive Advantage. J. Manag. 1991, 17, 99-120. [CrossRef]

23. Teece, D.J.; Pisano, G.; Shuen, A. Dynamic Capabilities and Strategic Management. Strateg. Manag. J. 1997, 18, 509-533. [CrossRef]

24. Malik, A.; Froese, F.J.; Sharma, P. Role of HRM in Knowledge Integration: Towards a Conceptual Framework. J. Bus. Res. 2020, 109, 524-535. [CrossRef]

25. Saha, N.; Gregar, A.; Sáha, P. Organizational Agility and HRM Strategy: Do They Really Enhance Firms' Competitiveness? Int. J. Organ. Leadersh. 2017, 6, 323-334. [CrossRef]

26. Kellner, A. Determinants of human resource management strategy in a franchise. In Case Studies in Work, Employment and Human Resource Management; Edward Elgar Publishing: Cheltenham, UK, 2020; pp. 32-37. ISBN 978-1-78897-559-9.

27. Mariappanadar, S. Sustainable Human Resource Management: Strategies, Practices and Challenges; Macmillan International Higher Education: London, UK, 2019; ISBN 978-1-137-53059-2.

28. Chapman, E.F.; Sisk, F.A.; Schatten, J.; Miles, E.W. Human Resource Development and Human Resource Management Levers for Sustained Competitive Advantage: Combining Isomorphism and Differentiation. J. Manag. Organ. 2018, 24, 533-550. [CrossRef]

29. Delery, J.E.; Doty, D.H. Modes of Theorizing in Strategic Human Resource Management: Tests of Universalistic, Contingency, and Configurational Performance Predictions. Acad. Manag. J. 1996, 39, 802-835. [CrossRef]

30. Lopez-Cabrales, A.; Valle-Cabrera, R. Sustainable HRM Strategies and Employment Relationships as Drivers of the Triple Bottom Line. Hum. Resour. Manag. Rev. 2020, 30, 100689. [CrossRef]

31. Hoffman, N.P. An Examination of the "Sustainable Competitive Advantage" Concept: Past, Present, and Future. Acad. Mark. Sci. Rev. 2000, 2000, 1-16.

32. Clemons, E.K. Resources, Platforms, and Sustainable Competitive Advantage: How to Win and Keep on Winning. In New Patterns of Power and Profit; Palgrave Macmillan: Cham, Switzerland, 2019; pp. 93-104. ISBN 978-3-030-00442-2.

33. Coyne, K.P. Sustainable Competitive Advantage-What It Is, What It Isn't. Bus. Horiz. 1986, 29, 54-61. [CrossRef]

34. Huang, K.-F.; Dyerson, R.; Wu, L.-Y.; Harindranath, G. From Temporary Competitive Advantage to Sustainable Competitive Advantage. Br. J. Manag. 2015, 26, 617-636. [CrossRef]

35. Silva, G.A.S.K.; Warnakulasuriya, B.N.F.; Arachchige, B.J.H. HR Practices: A Source of Sustainable Competitive Advantage or Competitive Parity-A Systematic Literature Review. Vidyodaya J. Manag. 2019, 5, 1-29.

36. Porter, M.E. Competitive Advantage: Creating and Sustaining Superior Performance; Free Press: New York, NY, USA, 1985 ; Volume 167.

37. Beal, R.M. Competitive Advantage: Sustainable or Temporary in Today's Dynamic Environment? Florida A\&M University: Tallahassee, FL, USA, 2001.

38. Barney, J.B.; Wright, P.M. On Becoming a Strategic Partner: The Role of Human Resources in Gaining Competitive Advantage. Hum. Resour. Manag. 1998, 37, 31-46. [CrossRef]

39. Delery, J.E.; Roumpi, D. Strategic Human Resource Management, Human Capital and Competitive Advantage: Is the Field Going in Circles? Hum. Resour. Manag. J. 2017, 27, 1-21. [CrossRef]

40. Velmurugan, S.; Akhilesh, K.B. Sustained Competitive Advantage: Strategic HRM Initiatives and Consequences in Indian Context. Int. J. Econ. Manag. Eng. 2013, 7, 2350-2358.

41. Gowen, C.R.; McFadden, K.L.; Tallon, W.J. On the Centrality of Strategic Human Resource Management for Healthcare Quality Results and Competitive Advantage. J. Manag. Dev. 2006, 25, 806-826. [CrossRef]

42. Progoulaki, M.; Theotokas, I. Human Resource Management and Competitive Advantage: An Application of Resource-Based View in the Shipping Industry. Mar. Policy 2010, 34, 575-582. [CrossRef]

43. Lee, J.; Kim, S.; Lee, J.; Moon, S. Enhancing Employee Creativity for A Sustainable Competitive Advantage through Perceived Human Resource Management Practices and Trust in Management. Sustainability 2019, 11, 2305. [CrossRef] 
44. Lin, Y.; Desouza, K.C.; Roy, S. Measuring Agility of Networked Organizational Structures via Network Entropy and Mutual Information. Appl. Math. Comput. 2010, 216, 2824-2836. [CrossRef]

45. Felipe, C.M.; Roldán, J.L.; Leal-Rodríguez, A.L. An Explanatory and Predictive Model for Organizational Agility. J. Bus. Res. 2016, 69, 4624-4631. [CrossRef]

46. Appelbaum, S.H.; Calla, R.; Desautels, D.; Hasan, L. The Challenges of Organizational Agility (Part 1). Ind. Commer. Train. 2017, 49, 6-14. [CrossRef]

47. Baškarada, S.; Koronios, A. The 5S Organizational Agility Framework: A Dynamic Capabilities Perspective. Int. J. Organ. Anal. 2018, 26, 331-342. [CrossRef]

48. Ahammad, M.F.; Glaister, K.W.; Gomes, E. Strategic Agility and Human Resource Management. Hum. Resour. Manag. Rev. 2020, 30, 100700. [CrossRef]

49. Barahma, M.M.A.; Disomimba, M.; Ali, K.; Al-Awlaqi, M.A. The Relationship between Strategy of Work-Life Quality and Sustainable Competitive Advantage: A Survey Study on in Yemeni Manufacturing Industries. J. Syst. Manag. 2020, 6, 27-54. [CrossRef]

50. Kale, E.; Aknar, A.; Başar, Ö. Absorptive Capacity and Firm Performance: The Mediating Role of Strategic Agility. Int. J. Hosp. Manag. 2019, 78, 276-283. [CrossRef]

51. Cunha, M.P.E.; Gomes, E.; Mellahi, K.; Miner, A.S.; Rego, A. Strategic Agility through Improvisational Capabilities: Implications for a Paradox-Sensitive HRM. Hum. Resour. Manag. Rev. 2020, 30, 100695. [CrossRef]

52. Crocitto, M.; Youssef, M. The Human Side of Organizational Agility. Ind. Manag. Data Syst. 2003, 103, 388-397. [CrossRef]

53. Dyer, L.; Ericksen, J. Dynamic Organizations: Achieving Marketplace Agility Through Workforce Scalability; Center for Advanced Human Resource Studies (CAHRS): Ithaca, NY, USA, 2006.

54. Xing, Y.; Liu, Y.; Boojihawon, D.K.; Tarba, S. Entrepreneurial Team and Strategic Agility: A Conceptual Framework and Research Agenda. Hum. Resour. Manag. Rev. 2020, 30, 100696. [CrossRef]

55. Nejatian, M.; Zarei, M.H.; Rajabzadeh, A.; Azar, A.; Khadivar, A. Paving the Path toward Strategic Agility: A Methodological Perspective and an Empirical Investigation. J. Enterp. Inf. Manag. 2019, 32, 538-562. [CrossRef]

56. Dabiri, S.A.; Gholami, A. Surveying the Effect of Strategic Agility on Gaining Competitive Advantage in Gachsaran Oil and Gas Exploitation Company. J. Renew. Nat. Resour. Bhutan 2015, 3, 196-207.

57. Almahamid, S.; Awwad, A.; McAdams, A.C. Effects of Organizational Agility and Knowledge Sharing on Competitive Advantage: An Empirical Study in Jordan. Int. J. Manag. 2010, 27, 387-404.

58. Chen, X. Impact of Business Intelligence and IT Infrastructure Flexibility on Competitive Advantage: An Organizational Agility Perspective; College of Business, University of Nebraska-Lincoln: Lincoln, NE, USA, 2012.

59. Al-Romeedy, B.S. Strategic Agility as a Competitive Advantage in Airlines-Case Study: Egypt Air. J. Fac. Tour. Hotels-Univ. Sadat City 2019, 3, 1-15.

60. Baron, R.M.; Kenny, D.A. The Moderator-Mediator Variable Distinction in Social Psychological Research: Conceptual, Strategic, and Statistical Considerations. J. Pers. Soc. Psychol. 1986, 51, 1173-1182. [CrossRef] [PubMed]

61. Wójcik, P. Exploring Links Between Dynamic Capabilities Perspective and Resource-Based View: A Literature Overview. Int. J. Manag. Econ. 2015, 45, 83-107. [CrossRef]

62. Teece, D.J. Explicating Dynamic Capabilities: The Nature and Microfoundations of (Sustainable) Enterprise Performance. Strateg. Manag. J. 2007, 28, 1319-1350. [CrossRef]

63. Yemeni Ministry of Industry and Trade. 2017. Available online: http:/ / www.yemen.gov.ye- / portal/Default.aspx?lias=www. yemen.gov.ye/portal/industry (accessed on 18 March 2020).

64. Laswar, N.M. Integration of Human Resource Strategy and Knowledge Management and Its Impact Organization Performance: A Field Study on Oil and Gas Companies in Yemen. Ph.D. Thesis, Sudan University of Science \& Technology, Khartoum, Sudan, 2016.

65. Chen, C.-J.; Huang, J.-W. Strategic Human Resource Practices and Innovation Performance-The Mediating Role of Knowledge Management Capacity. J. Bus. Res. 2009, 62, 104-114. [CrossRef]

66. Balkin, D.B.; Gomez-Mejia, L.R. Toward a Contingency Theory of Compensation Strategy. Strateg. Manag. J. 1987, 8, 169-182. [CrossRef]

67. Jarbi, A. The Effect of Human Resource Management on the Creation of Organization's Sustainable Competitive Advantage: A Case Study on Saidal Pharmaceutical Complex, Kusantinah Branch. Ph.D. Thesis, Université de Sétif, Setif, Algeria, 2013.

68. Alanizi, S.; Alfadhel, S. The Philosophy of Work Life Quality in the Third Millinium Organizations. J. Econ. Adm. Sci. 2007, $13,68-85$.

69. Schuler, R.S.; Jackson, S.E. Linking Competitive Strategies with Human Resource Management Practices. Acad. Manag. Perspect. 1987, 1, 207-219. [CrossRef]

70. Alabdi, A.R.J. Strategic Agility: Strategic Approach to Improve Employees' Engagement: A Case Study on a Sample of Manufacturing Companies. AL GHAREE Econ. Adm. Sci. 2012, 8, 147-174.

71. Park, Y.; Sawy, O.E.; Fiss, P. The Role of Business Intelligence and Communication Technologies in Organizational Agility: A Configurational Approach. J. Assoc. Inf. Syst. 2017, 18. [CrossRef]

72. Shabaan, M.R. Intellectual Capital and Its Role in the Creation of Sustainable Competitive Advantage: A Case Study on the Palestinian Telecommunication Companies. Master's Thesis, Islamic University, Gazza, Palestine, 2011. 
73. Hair, J.; Hult, G.T.M.; Ringle, C.M.; Sarstedt, M. A Primer on Partial Least Squares Structural Equation Modeling, 2nd ed.; SAGE Publications, Inc: Los Angeles, CA, USA, 2016; ISBN 978-1-4833-7744-5.

74. Nadeau, J.; Casselman, R.M. Competitive Advantage with New Product Development: Implications for Life Cycle Theory. J. Strateg. Mark. 2008, 16, 401-411. [CrossRef]

75. Giannakis, D.; Chalikias, I.; Tsirigoti, E. The Effect of Sales and HRM Strategic Alignment on a Corporate Sustainable Competitive Advantage: The Significant Role of the HR Business Partner. Int. J. Innov. Manag. Technol. 2019, 10, 207-218. [CrossRef]

76. Obeidat, B.Y.; Tarhini, A.; Masa'deh, R. A Jordanian Empirical Study of the Associations among Transformational Leadership, Transactional Leadership, Knowledge Sharing, Job Performance, and Firm Performance: A Structural Equation Modelling Approach. J. Manag. Dev. 2016, 35, 681-705. [CrossRef]

77. Pahuja, S.; Dalal, R.C. Achieving Competitive Advantage through HR Practices: A Case Study. J. Strateg. Hum. Resour. Manag. 2012, 1, 35-43.

78. Murungi, A.M. Influence of Strategic Agility on Competitive Capability of Private Universities in Kenya. Master's Thesis, University of Nairobi, Nairobi, Kenya, 2015. 